\title{
Neurobiological and Psychophysical Mechanisms Underlying the Oral Sensation Produced by Carbonated Water
}

\author{
C. T. Simons, ${ }^{1,2}$ J. -M. Dessirier, ${ }^{1,2}$ M. lodi Carstens, ${ }^{1}$ M. O'Mahony, ${ }^{2}$ and E. Carstens ${ }^{1}$ \\ ${ }^{1}$ Section of Neurobiology, Physiology, and Behavior, and ${ }^{2}$ Department of Food Science and Technology, University of \\ California, Davis, California 95616
}

Carbonated drinks elicit a sensation that is highly sought after, yet the underlying neural mechanisms are ill-defined. We hypothesize that $\mathrm{CO}_{2}$ is converted via carbonic anhydrase into carbonic acid, which excites lingual nociceptors that project to the trigeminal nuclei. We investigated this hypothesis using three methodological approaches. Electrophysiological methods were used to record responses of single units located in superficial laminae of the dorsomedial aspect of trigeminal subnucleus caudalis (Vc) evoked by lingual application of carbonated water in anesthetized rats. After pretreatment of the tongue with the carbonic anhydrase inhibitor dorzolamide, neuronal responses to carbonated water were significantly attenuated, followed by recovery. Using c-Fos immunohistochemistry, we investigated the distribution of brainstem neurons activated by intraoral carbonated water. Fos-like immunoreactivity (FLI) was significantly higher in the superficial laminae of dorsomedial and ventrolateral Vc in animals treated with carbonated water versus controls. Dorzolamide pretreatment significantly reduced $\mathrm{FLI}$ in dorsomedial Vc. We also examined the sensation elicited by carbonated water in human psychophysical studies. When one side of the tongue was pretreated with dorzolamide, followed by bilateral application of carbonated water, a significant majority of subjects chose the untreated side as having a stronger sensation and assigned significantly higher intensity ratings to that side. Dorzolamide did not reduce irritation elicited by pentanoic acid. The present data support the hypothesis that carbonated water excites lingual nociceptors via a carbonic anhydrase-dependent process, in turn exciting neurons in Vc that are presumably involved in signaling oral irritant sensations.

Key words: trigeminal nucleus caudalis; c-Fos; single-unit recording; rat; carbonated water; carbonic anhydrase; oral irritation; psychophysics; two-alternative forced-choice
The allure of carbonated beverages is supported by the $\$ 55$ billion generated in retail sales in 1997 (Beverage Digest, 1998). Despite this huge fiscal impact, relatively little is known about the neural mechanisms underlying the sensation elicited by carbonation. Carbon dioxide applied to the corneal surface (Chen et al., 1997), nasal epithelium (Cain and Murphy, 1980; Anton et al., 1991a,b, 1992; Thürauf et al., 1991, 1993; Peppel and Anton, 1993), or skin (Steen et al., 1992) excites nociceptive fibers and evokes pain sensation in humans. $\mathrm{CO}_{2}$ interacts with water in a reaction catalyzed by carbonic anhydrase to form carbonic acid, which presumably stimulates chemosensitive nociceptors (Lingueglia et al., 1997; Waldmann et al., 1997a,b). Indeed, carbonic anhydrase inhibitors attenuate the activity elicited by saturated $\mathrm{CO}_{2}$ solutions in cutaneous (Steen et al., 1992) and chorda tympani nerve fibers (Kawamura and Adachi, 1967; Komai et al., 1994).

It has been debated whether the oral sensation produced by carbonated beverages is primarily chemogenic or rather mechanical in nature because of bursting $\mathrm{CO}_{2}$ bubbles (Yau and McDaniel, 1990, 1991; Green, 1992; Komai and Bryant, 1993). Several lines of evidence argue against the mechanical hypothesis. Tingling, mouth-burn, pricking, and other sensations elicited by

Received March 11, 1999; revised July 1, 1999; accepted July 6, 1999.

This work was supported by California Tobacco Disease-Related Research Program Grant 6RT-0231 and the National Institutes of Health, National Institute of Neurological Disorders and Stroke Grant NS-35778.

Correspondence should be addressed to E. Carstens, Section of Neurobiology, Physiology, and Behavior, University of California, Davis, One Shields Avenue, Davis, CA 95616.

Copyright (C) 1999 Society for Neuroscience $\quad 0270-6474 / 99 / 198134-11 \$ 05.00 / 0$ carbonated water under normal atmospheric conditions were essentially unchanged when subjects ingested the carbonated water under hyperbaric conditions (3.4 atmosphere) in which bubble formation was prevented (McEvoy, 1998). Furthermore, subjects consistently chose poignant over tactile descriptors in describing the sensation elicited by carbonated water and reported a "burning and tingling-numbness" aftersensation long after the carbonated water had been expectorated (Green, 1992). Finally, the carbonic anhydrase blocker acetazolamide was reported to reduce the "fizziness" of carbonated drinks (Graber and Kelleher, 1988) and the response of lingual nerve nociceptive afferents to carbonated water (Komai and Bryant, 1993).

The present study sought to further characterize the mechanisms underlying the oral sensation elicited by carbonated water using three distinct methodologies. The first involved single-unit recordings from trigeminal subnucleus caudalis (Vc). Primary afferent fibers of nociceptors originating in the orofacial region project to Vc (Hayashi, 1985; Jacquin et al., 1986; Komai and Bryant, 1993; Coimbra and Coimbra, 1994; Strassman and Vos, 1993), as well as other trigeminal subnuclei (see Discussion), in which they activate second-order neurons presumably involved with relaying nociceptive information to higher centers (Kruger and Michel, 1962; Yokota, 1975; Amano et al., 1986; Strassman and Vos, 1993; Carstens et al., 1995, 1998; Raboisson et al., 1995). In particular, neurons in superficial laminae of the dorsomedial aspect of $\mathrm{Vc}$ are activated by application of irritant chemicals to the tongue (Carstens et al., 1995, 1998). We tested the hypothesis that carbonated water excites neurons in $\mathrm{Vc}$ by activating intraoral nociceptors via a carbonic anhydrase-dependent mechanism. 
Lingual application of a variety of irritant chemicals resulted in a similar distribution of c-Fos expression in several brainstem regions, including dorsomedial $\mathrm{Vc}$, ventrolateral $\mathrm{Vc}$, nucleus of the solitary tract (NTS), area postrema (AP), and ventrolateral medulla (Carstens et al., 1995). Carbonated water might conceivably activate neurons in these and/or other brainstem areas. Moreover, defining which brainstem nuclei are activated by $\mathrm{CO}_{2}$ may shed some light on its interaction with other irritants and tastants (Cometto-Muñiz et al., 1987; Yau and McDaniel, 1992; Cowart, 1998). We therefore used the method of c-Fos immunohistochemistry to investigate the brainstem distributions of neurons activated by carbonated water and whether it is prevented by pretreatment with a carbonic anhydrase inhibitor dorzolamide.

Finally, to provide a perceptual correlate for the neurobiological findings, we conducted human psychophysical studies to determine whether dorzolamide pretreatment selectively reduces the sensation elicited by carbonated water but not other acids.

\section{MATERIALS AND METHODS}

\section{Experiment 1: electrophysiology}

Animals. Ten adult male Sprague Dawley rats (Simonsen Inc., Gilroy, CA), weighing between $380-480 \mathrm{gm}$, were used in the experiments. The animals were housed one per cage in a room maintained on a $12 \mathrm{hr}$ light/dark cycle and an ambient temperature of $21 \pm 2^{\circ} \mathrm{C}$. Food and water were available ad libitum. To obviate any possible effects of circadian rhythms (Lotsch et al., 1998), the experiments were always started between 12:00 P.M. and 2:00 P.M. All protocols were approved by the University of California (UC) Davis Animal Use and Care Advisory committee.

Surgery. Each animal was anesthetized with thiopental $(80 \mathrm{mg} / \mathrm{kg}$, i.p.). Core body temperature was maintained at $\sim 37^{\circ} \mathrm{C}$ by placing the animal on a heating pad. A tracheotomy was performed, and a tracheal cannula was implanted. Similarly, a catheter was inserted into the jugular vein so thiopental could be inf used intravenously $\left(10 \mathrm{mg} \cdot \mathrm{kg}^{-1} \cdot \mathrm{d}^{-1}\right)$ during the course of the experiment to maintain anesthesia; the rate was increased briefly if the rat showed signs of insufficient anesthesia, such as change in heart rate or reflexive movement in response to a noxious stimulus. The occipital bone and upper cervical spine were visualized via a midline incision, and the base of the cerebellum, lower brainstem, and $\mathrm{C} 1$ spinal cord were exposed by removal of the caudal portion of the occipital bone and atlas. Each animal was then placed in a stereotaxic frame (Kopf Instruments, Tujunga, CA) with the head slightly ventroflexed and the upper cervical spine immobilized with a vertebral clamp. The dura mater was removed, and an agar (Difco, Detroit, MI) pool was formed over the brainstem. After the agar hardened, an opening was cut in an area overlying the target recording site and filled with $0.9 \%$ saline. Finally, a small clip was placed over the upper and lower incisors in such a way as to keep the mouth open and the tongue easily accessible. Isotonic saline was applied frequently to the tongue to prevent desiccation.

Recording. A Teflon-insulated tungsten recording microelectrode $(\sim 10$ $\mathrm{M} \Omega$; F. Haer Inc., Brunswick, ME) was advanced into the brainstem in $5 \mu \mathrm{m}$ steps using a hydraulic microdrive (Kopf Instruments). Extracellular single-unit activity was amplified and displayed by conventional means and fed via an analog-to-digital converter (Microstar Industries, Seattle, WA) to a computer for analysis and storage. Unitary action potentials were discriminated, counted, and displayed in peristimulustime histogram (PSTH) format (bin width of $1 \mathrm{sec}$ ), using software developed in Erlangen, Germany (Forster and Handwerker, 1990).

Recordings were made from single units in the superficial layers of the dorsomedial aspect of $\mathrm{Vc}$ that responded to ipsilateral mechanical (touch, pressure, pinch) and heat $\left(\sim 54^{\circ} \mathrm{C}\right)$ stimuli, and carbonated water was applied bilaterally to the dorsoanterior one-third of the tongue. The search for units was restricted to an area previously shown to contain neurons responsive to noxious chemical stimulation of the tongue (Carstens et al., 1995, 1998). Briefly, this region included the area approximately between $0.5 \mathrm{~mm}$ rostral and $2 \mathrm{~mm}$ caudal to the obex, and $1.5 \mathrm{~mm}$ lateral. Tongue units responsive to mechanical stimulation were readily observed at depths ranging from 50 to $500 \mu \mathrm{m}$ below the medullary surface.

Stimulation. The stimuli used to induce activity in trigeminal neurons included noxious heat $\left[\right.$ hot $\left(\sim 54^{\circ} \mathrm{C}\right)$ deionized water], buffered hydro-
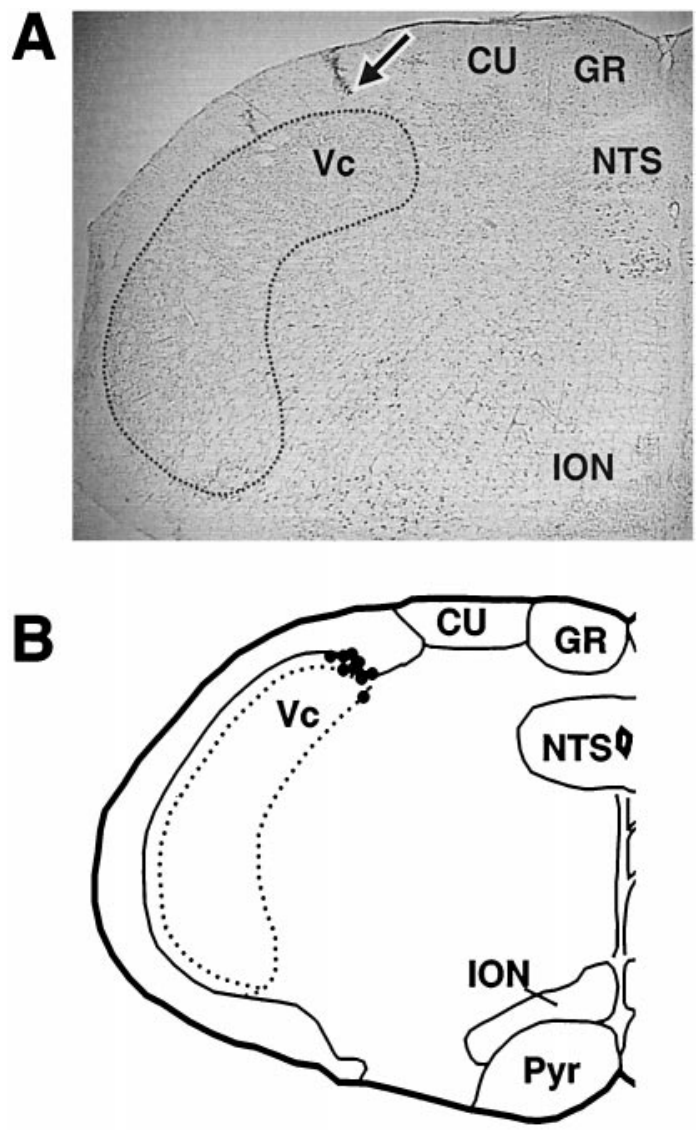

Figure 1. Histologically recovered recording sites in superficial laminae of the dorsomedial Vc. A, Photomicrograph of lesion site in Vc (arrow). B, Recording sites $(\bullet)$ for nine units, compiled on representative section of brainstem. Lateral dashed lines indicate approximate border of laminae I-II, and medial dashed lines indicate approximate ventral border of $\mathrm{Vc}$. $C U$, Cuneate nucleus; $G R$, nucleus gracilis; $I O N$, inferior olivary nucleus; Pyr, pyramid.

chloric acid, pH 1 (Fisher Scientific, Pittsburgh, PA), and commercially available carbonated water, pH $3.4 \pm 0.1$ (Safeway Foods, Inc., Pleasanton, $\mathrm{CA}$ ).

A syringe was used to apply stimuli bilaterally to the anterodorsal surface of the tongue in $\sim 0.1 \mathrm{ml}$ volume (except carbonated water, which was applied continuously at the rate of $\sim 0.1 \mathrm{ml} / \mathrm{sec}$ ). All chemicals were delivered at room temperature to avoid any confounding effects of cooling or heating. The acid stimulus was applied as a bolus, left on for $30 \mathrm{sec}$, and then immediately rinsed with $\sim 2 \mathrm{ml}$ of isotonic saline. Freshly opened carbonated water was applied continuously for $30 \mathrm{sec}$, followed immediately by a saline rinse.

In cells showing stable responses to carbonated water applied three times in succession at 5 min interstimulus intervals, the carbonic anhydrase inhibitor dorzolamide hydrochloride $(22.3 \mathrm{mg} / \mathrm{ml}$; Merck, West Point, PA) was then delivered. Dorzolamide was applied three times (at $0,5$, and $10 \mathrm{~min})$ as a bolus $(\sim 0.1 \mathrm{ml})$ to the dorsal lingual epithelium. After the last application, the drug was left on the lingual surface for 10 min, after which the response of the unit to carbonated water was recorded again. If the response of the cells to carbonated water was reduced after dorzolamide, we continued testing with carbonated water at $\sim 10 \mathrm{~min}$ intervals to determine whether the response recovered to predorzolamide levels.

Histology. After the completion of each recording session, an electrolytic lesion was made at the recording site by passing current (6 V DC) through the microelectrode for $20 \mathrm{sec}$. Animals were then killed with a lethal overdose of thiopental (intravenously), and the brains were removed and post-fixed in $10 \%$ formalin. The brainstems were frozen, cut into $50 \mu \mathrm{m}$ sections, collected on glass slides, counterstained with neutral red, and examined under a light microscope. Lesions were identified and collectively plotted onto a representative brainstem section (Fig. 1). 
Data analysis. Three conditions were used in these experiments (control, control plus dorzolamide, and recovery). Data from each unit under each condition were integrated over the initial $15 \mathrm{sec}$ [spontaneous activity before carbonated water application $(0-15 \mathrm{sec})]$ and again over the next $15 \mathrm{sec}$ period $(16-31 \mathrm{sec})$ during the initial period of carbonated water application and before any significant adaptation occurred. The effects of dorzolamide treatment were analyzed across all units using a Student's paired $t$ test to compare responses to carbonated water before and after dorzolamide application; $p<0.05$ was taken to be significant.

\section{Experiment 2: immunohistochemistry}

Animals. Twenty-four adult male Sprague Dawley rats (Simonsen Inc.), weighing between $400-500 \mathrm{gm}$, were used in the experiments. The animals were housed in the same manner as described above. Twentyfour hours before the experiment, the animals were brought to the laboratory and acclimated to the experimental environment. The experimental protocol was approved by the UC Davis Animal Use and Care Advisory committee.

Stimulation. Animals were anesthetized with sodium pentobarbital (65 $\mathrm{mg} / \mathrm{kg}$, i.p.). Once a proper plane of anesthesia was attained as assessed by areflexia, a clip was placed gently over the upper and lower incisors to hold the mouth open slightly. Parafilm (American National Can, Neenah, WI) was gently placed under the tongue to prevent stimuli from contacting the gingiva and other oral surfaces. Animals received the following chemical stimuli. (1) Carbonated water, pH 3.4 \pm 0.1 (Safeway Foods Inc.), which was flowed onto the lingual surface at a rate of $\sim 10$ $\mathrm{ml} / \mathrm{min}$ for $10 \mathrm{~min}(n=6)$. (2) Dorzolamide hydrochloride $(22.3 \mathrm{mg} / \mathrm{ml}$; Merck), applied topically three times at $5 \mathrm{~min}$ intervals by bolus application $(0.1 \mathrm{ml})$ to the dorsal surface of the tongue $(n=11)$. The third application was left on for $10 \mathrm{~min}$, after which carbonated water was applied in the same manner as above. (3) Isotonic saline control, applied in the same manner as dorzolamide $(n=5)$. This control group allowed us to assess the degree of stimulation potentially caused by dorzolamide application. (4) A flat water control $(n=7)$. The flat water was made by exposing the same carbonated water as used previously to air for $24 \mathrm{hr}$ and was assessed qualitatively by the investigators. The flat water was flowed at the same rate as the carbonated water; this group controlled for any mechanical activation of lingual fibers by the flow. (5) Unstimulated controls $(n=6)$. This last control group was perfused $2 \mathrm{hr}$ after induction of anesthesia without any type of stimulation; this allowed us to determine basal levels of c-Fos expression. After the stimulation procedure, the incisor clip was carefully removed, and the animals were allowed to lie quietly on a heating pad until the perfusion.

Staining. Two hours after the onset of stimulation with carbonated water (or saline or flat water), the rats were perfused through the heart with $250 \mathrm{ml}$ of PBS, followed by $500 \mathrm{ml}$ of $4 \%$ paraformaldehyde. The brains were removed and post-fixed for $24-48 \mathrm{hr}$, after which they were placed in a $30 \%$ sucrose solution for cryoprotection. One to $2 \mathrm{~d}$ later, the brainstems were frozen, cut into $50 \mu \mathrm{m}$ sections, and processed for c-Fos immunohistochemistry. The sections were first blocked with $3 \%$ normal goat serum (in PBS with $0.3 \%$ Triton X-100) for $1 \mathrm{hr}$ and then exposed to the primary c-Fos antibody (diluted 1:50,000; Arnel Products Inc., New York, NY) for 24-36 hr. The primary antibody was removed, sections were washed, and the secondary biotinylated goat anti-rabbit antibody (Vector Laboratories, Burlingame, CA) was applied. One hour later, this antibody was removed, and the sections were washed again and then subjected to an avidin-biotin-peroxidase reaction (Vector Laboratories). Finally, cell nuclei expressing Fos-like immunoreactivity (FLI) were stained black by a nickel diaminobenzidine reaction. Brainstem sections were mounted on gelatin-coated slides, air-dried, cleared in alcohol, and coverslipped. The locations of cell nuclei expressing FLI were observed and quantified under the light microscope (E-400; Nikon, Tokyo, Japan).

Data analysis. The numbers of cell nuclei with FLI were counted in five areas of the brainstem shown previously to be responsive to irritant chemicals placed on the tongue (Carstens et al., 1995). Specifically, these areas were (1) the dorsomedial aspect of $\mathrm{Vc},(2)$ the ventrolateral aspect of Vc, (3) the NTS between the level of the pyramidal decussation caudally and area postrema rostrally, (4) a region of the ventolateral medulla near the lateral reticular nucleus, and (5) the AP (see Fig. 5). Brainstem sections were selected for quantification of FLI so that comparisons with sections at corresponding levels of the brainstem could be made between animals. The investigator who selected sections and did the counts was blinded as to the experimental treatment. For illustrations, representative sections were imaged with a color video camera
(DC-330; Dage-MTI, Michigan City, IN) using Scion Image software (Scion Corp., Frederick, MD) and imported to commercially available graphical software (Corel Draw; Corel, Ottawa, Ontario, Canada), which allowed locations of FLI to be plotted directly and accurately onto a computer-generated trace of the section. Between-treatment group comparisons of mean bilateral counts of FLI for each region of interest were statistically analyzed by an unpaired $t$ test, with $p<0.05$ considered to be significant.

\section{Experiment 3: human psychophysics}

Subjects. Twenty-one subjects (10 male, 11 female) ranging in age from 19 to 29 years participated in the experiments; all were students at UC Davis. The protocol was approved by the UC Davis Human Subjects Review committee. Subjects were asked to refrain from eating, drinking, or smoking for at least $1 \mathrm{hr}$ immediately before the experiment (three subjects reported to be smokers). Subjects participated in a single session that lasted $<30 \mathrm{~min}$.

Stimuli. The carbonic anhydrase inhibitor dorzolamide hydrochloride (22.3 mg/ml; Merck) was used at full strength. A control solution was prepared that approximately matched the dorzolamide in viscosity $[1 \%$ methyl cellulose (Sigma, St. Louis, MO) in deionized water] and taste (1.26 mm quinine $\mathrm{HCl}$; BDH Chemicals, Poole, UK). The control solution was carefully chosen so as to minimize bias and to equalize any bitter-induced inhibition of $\mathrm{CO}_{2}$ pungency as described previously by Cometto-Muñiz et al. (1987). The carbonated water stimulus, pH $3.4 \pm$ 0.1 , was prepared in our laboratory by pressurizing ( $50 \mathrm{psi})$ deionized water at room temperature with $\mathrm{CO}_{2}(95 \%)$ for $2 \mathrm{~d}$. Pentanoic acid (Sigma) was diluted with deioinized water to a final concentration of 200 mm. To test lingual sensitivity to tactile stimulation, a von Frey monofilament (Stoelting, Chicago, IL) calibrated to $0.229 \mathrm{mN}$ was used.

Stimulus application. The primary purpose of this experiment was to determine whether previous treatment with the carbonic anhydrase inhibitor dorzolamide attenuated the perceived sensation caused by the application of carbonated water to the human lingual surface. To this end, we used a half-tongue protocol similar to one used previously (Dessirier et al., 1997, 1998). Briefly, a filter paper disk (2.5 cm diameter; Whatman International Ltd., Maidstone, UK) was cut in half, saturated with dorzolamide, and applied, with forceps, to one side of the dorsal surface of the tongue. The control solution (1.26 mm quinine $\mathrm{HCl}$ in $1 \%$ methyl cellulose) was simultaneously applied, in the same manner, to the opposite side of the tongue; the side receiving dorzolamide or control was counterbalanced across subjects. Because the application of dorzolamide increases salivary flow rate, which might cause confounding effects because of the mixing of chemicals on the lingual surface, a suction device (Saliva Ejector, 6 inch clear; Sullivan Dental Products Inc., Sacramento, CA) was used by subjects to remove excess saliva. Subjects were allowed to use the device at any time, except for the $15 \mathrm{sec}$ immediately before performing the two-alternative forced-choice (2-AFC) or rating tests (see below). This device has been used in previous experiments and was demonstrated to be free of any confounding effects (Dessirier et al., 1997). The filter papers were left on the tongue for $5 \mathrm{~min}$, after which time subjects were asked to rinse their mouth with deionized water. After the rinse procedure, lingual sensitivity to $\mathrm{CO}_{2}$ was tested by flowing carbonated water at a rate of $20 \mathrm{ml} / \mathrm{min}$ bilaterally over the dorsal surface of the tongue for $5 \mathrm{sec}$ on one trial and $15 \mathrm{sec}$ on the next. It was noted in pilot studies that increasing the duration of flow diminished the differences between the treated and untreated sides of the tongue. Because we wanted to maximize sensitivity to the carbonated water stimulus, durations were not counterbalanced across subjects; all subjects completed the $5 \mathrm{sec}$ trial before completing the $15 \mathrm{sec}$ trial.

We used a 2-AFC methodology in which we asked subjects to indicate the side of the tongue perceived to have the strongest sensation elicited by carbonated water during a $5 \mathrm{sec}$ application and the last $5 \mathrm{sec}$ of a 15 sec application. In the previous case, subjects were told to concentrate on the sensation elicited by the carbonated water during the entire $5 \mathrm{sec}$ application, whereas, in the latter case, subjects were told to disregard any sensation during the first $10 \mathrm{sec}$ and compare the sensations elicited on either side of the tongue only during the last $5 \mathrm{sec}$ (at which time they were prompted). In addition to the forced-choice, subjects were also asked, at each time point ( 5 and $15 \mathrm{sec}$ ), to independently rate the intensity of the sensation elicited by carbonated water on each side of the tongue using a $0-10$ category scale ( 0 , no sensation; 10, intense sensation).

Although we believed that dorzolamide would selectively attenuate $\mathrm{CO}_{2}$ irritation by blocking carbonic anhydrase activity, it was conceivable 

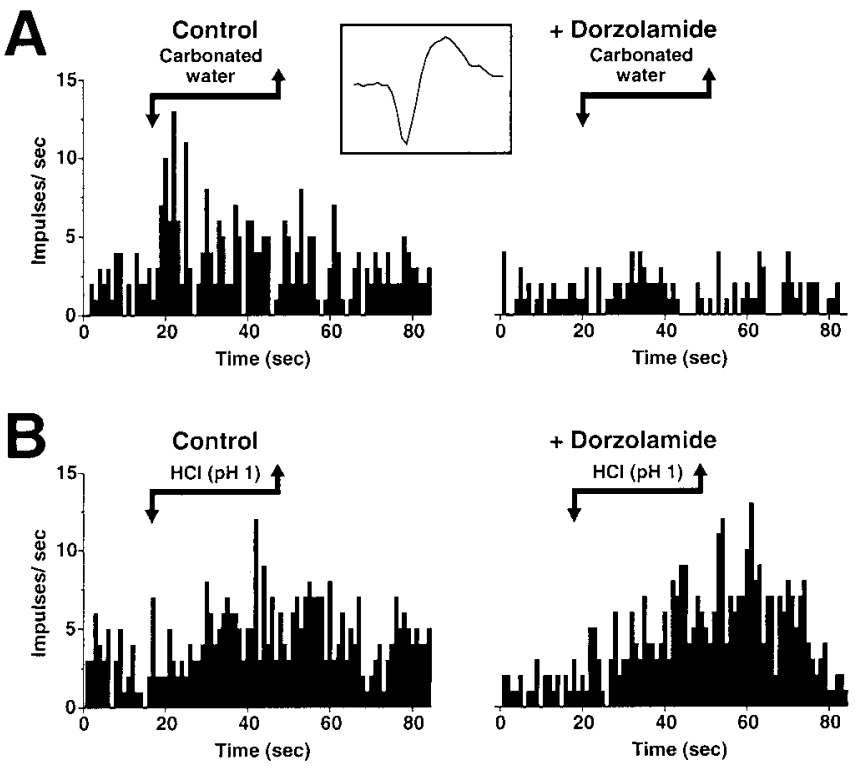

that the treatment could have nonspecific effects, thereby blocking the sensations induced by other chemical or tactile stimuli. Therefore, to test this possibility, separate control experiments were conducted using acid (200 mM pentanoic acid) and tactile stimuli (von Frey filament; 0.229 $\mathrm{mN}$ ). The pentanoic acid was chosen because it had an oil-water partitition coefficient similar to $\mathrm{CO}_{2}$. The order in which these treatments were given was counterbalanced across subjects. For acidic stimuli, two filter paper disks (1.0 cm diameter; Whatman International Ltd.), each saturated with $15 \mu \mathrm{l}$ of pentanoic acid, were placed, using forceps, on each side of the tongue in a corresponding area that had been previously treated with dorzolamide or control solution. Subjects were told to close their mouth, and after $\sim 5 \mathrm{sec}$, the filter papers were removed and subjects were again asked to perform a 2-AFC and indicate the side of the tongue for which a stronger tingling-burning sensation was perceived. They were asked to disregard sour taste when making this judgment. In addition, they again used the same $0-10$ category scale to rate the intensity of the sensation perceived on each side of the tongue.

Tactile sensitivity of the tongue was tested by applying the von Frey filament to the dorzolamide-treated side, the untreated (control) side, or not at all (blank), in randomized order. Each condition was tested 10 times for a total of 30 trials. Subjects responded by indicating whether or not they felt the stimulus and whether or not they were sure of their response. From these data, response matrices for each subject were constructed from which indices representing the tactile sensitivity on each side of the tongue were calculated (R-index) (O'Mahony, 1992).

To show that the effect of dorzolamide was present when subjects performed the acid and tactile control tests, carbonated water was applied again at the end of the session. As before, subjects performed a 2 -AFC test and rated the intensity of carbonation on the treated and untreated sides of the tongue at $5 \mathrm{sec}$.

Finally, it is possible that subjects chose a side as having a stronger sensation elicited by carbonation, not because of the perception encountered, but because of some cue elicited by the dorzolamide or control treatment. Thus, at the end of each experimental session, two filter papers $(2.5 \mathrm{~cm}$ diameter, cut in half) were again saturated with dorzolamide or control solution, placed onto both sides of the tongue in random order, and left for 5-10 sec. After removal of the papers, subjects were asked to select the side they thought contained the chemical responsible for reducing the intensity of the sensation evoked by carbonated water. If no taste or textural cues were consistently used by subjects, it would be expected that subjects would choose randomly between the dorzolamide or control; this would result in each chemical being selected $50 \%$ of the time.

Data analysis. A binomial analysis was used to determine whether a significant majority of subjects chose a particular side (dorzolamidetreated vs nontreated) as having a stronger carbonation- or acid-evoked sensation and a d' analysis (Ennis, 1993) was also performed to determine the strength and significance of the effect using the method of Bi et al. (1997); $p<0.05$ was considered significant in all cases. To determine

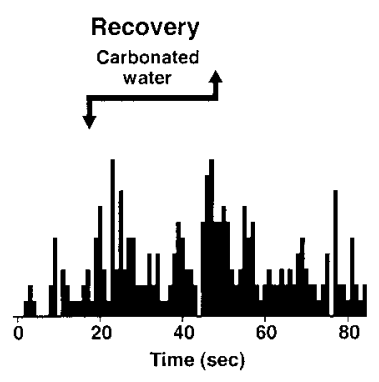

Figure 2. Example of dorzolamide blockade of unit response to carbonated water. $A$, Carbonated water. Left PSTH (bin width, 1 $\mathrm{sec}$ ) shows response of the unit to carbonated water flowed continuously for $30 \mathrm{sec}$ (arrows) on the anterior surface of the tongue. The middle PSTH shows reduction in the response of the same neuron to carbonated water after pretreatment of the tongue with dorzolamide. PSTH on right shows recovery of response. Inset shows example of action potential waveform. $B$, PSTHs of the responses of the same unit to $\mathrm{HCl}$ (left) was not reduced after dorzolamide application (right). $C$, Recording site (-) on drawing of brainstem section through Vc. Abbreviations as in Fig. 1.

whether the intensity of the sensation elicited by carbonated water or pentanoic acid varied significantly between the dorzolamide- and control-treated sides of the tongue, mean intensity scores for each side were calculated under each condition, and a paired Student's $t$ test was used. R-indices for the treated and untreated sides of the tongue were calculated, and a $t$ test was used to determine whether there was a significant difference between the two.

\section{RESULTS}

\section{Experiment 1: electrophysiology}

Ten units responded to non-noxious pinch (as assessed by the experimenter when the same stimulus was applied to the webbing between fingers), noxious heat $\left(54^{\circ} \mathrm{C}\right)$, and carbonated water and thus were categorized as wide dynamic range. Of these, two also responded to hydrochloric acid, $\mathrm{pH}$ 1. Spontaneous activity in these units was generally low, having a discharge frequency that seldom exceeded $5 \mathrm{~Hz}$. The receptive field was usually limited to the tongue, but in three units, also included portions of the ipsilateral upper and/or lower lip and cheek. Recording sites were histologically localized to Vc. A photomicrograph of a lesion site is shown in Figure $1 A$, and all recovered sites are compiled on a representative brainstem section in Figure $1 B$. They were located in the superficial layers of the dorsomedial aspect of Vc ipsilateral to the receptive field, consistent with our previous results (Carstens et al., 1998).

Dorzolamide treatment significantly reduced the response of these units to carbonated water $(t$ test; $p<0.001)$. Moreover, the treatment appeared to be specific to acid production from $\mathrm{CO}_{2}$ because the response from two cells to $\mathrm{HCl}$ did not change after dorzolamide application. An example is shown in Figure $2 A$ in which the response of a single unit to carbonated water (left PSTH) is reduced after dorzolamide treatment (middle PSTH), followed by recovery of the response (right PSTH). Figure $2 B$ shows that the response of this same unit to the acid stimulus (left PSTH) was not affected by pretreatment with dorzolamide (right PSTH).

Averaged PSTHs for the 10 units are shown in Figure 3. No significant differences were seen in the spontaneous firing rate of cells before and after dorzolamide treatment ( $t$ test; $p=0.48$ ). However, the activity induced in cells by carbonated water after dorzolamide was significantly lower compared with the response 

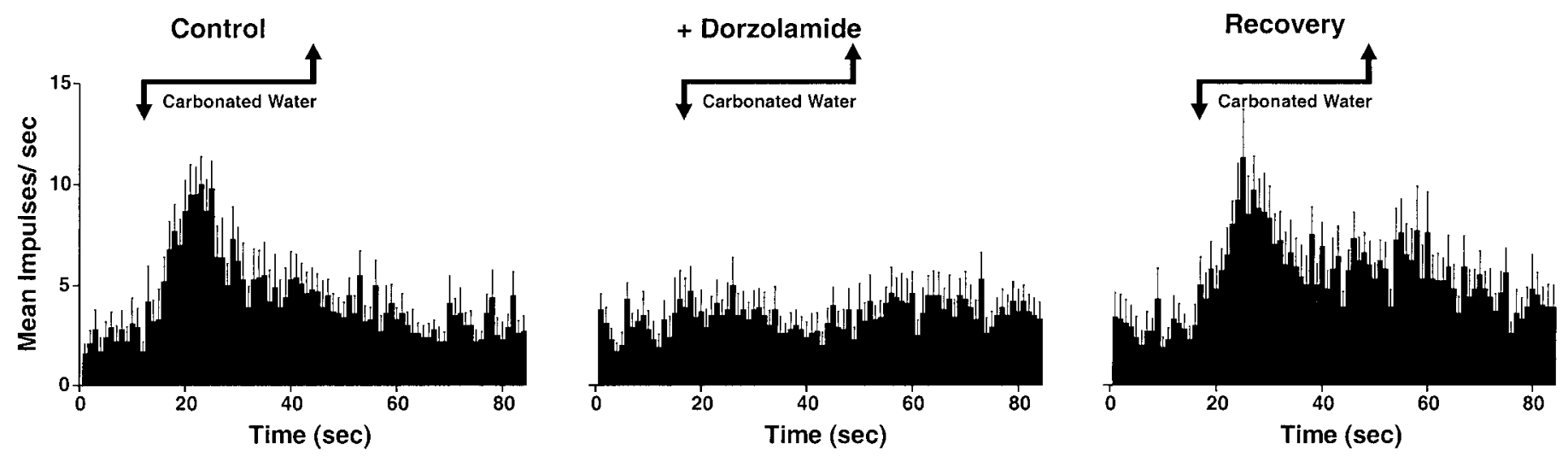

Figure 3. Mean PSTH (bin width, $1 \mathrm{sec}$ ) of 10 neurons to carbonated water applied for 30 sec to the dorsal surface of the rat tongue. Left PSTH, Mean response before the application of dorzolamide. Middle PSTH, Mean response after dorzolamide. Right PSTH, Recovery from the effect of dorzolamide. Spontaneous activity was not subtracted. Error bars indicate SEM.

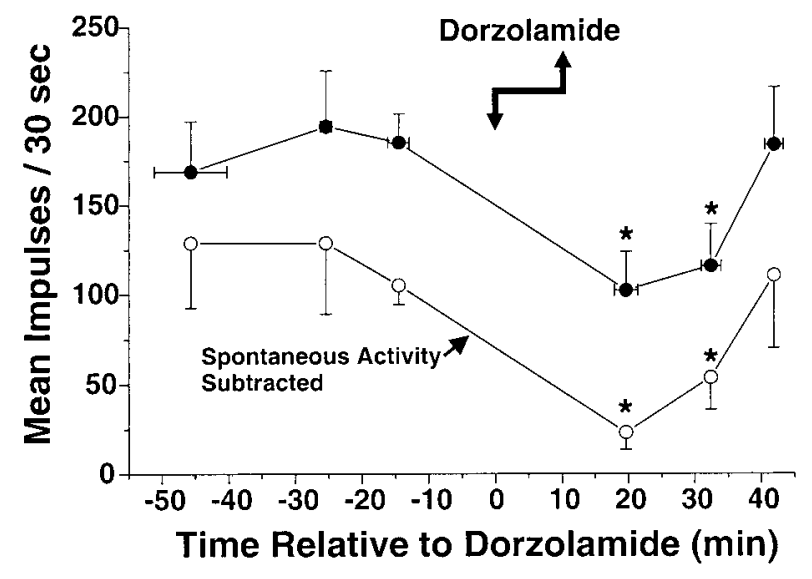

Figure 4. Time course of effect of dorzolamide. Graph plots mean responses of 10 units to application of carbonated water versus time relative to application of dorzolamide (indicated by arrows). $\bullet$, Spontaneous activity not subtracted; $\bigcirc$, spontaneous activity (total number of impulses during $30 \mathrm{sec}$ before application of carbonated water) subtracted from evoked response (total number of impulses during $30 \mathrm{sec}$ stimulus period). Error bars indicate SEM. ${ }^{*} p<0.05$, significantly different from predorzolamide level; $t$ test.

of the cells before dorzolamide ( $t$ test; $p<0.001)$. The effect of dorzolamide treatment was reversible because the response to carbonated water recovered after $\sim 40 \mathrm{~min}$ (right PSTH), at which time neither spontaneous activity nor the response to carbonated water were significantly different compared with predorzolamide levels ( $t$ test; $p=0.68$ and $p=0.65$, respectively). Figure 4 plots mean responses to carbonated water versus time, without $(-)$ and with $(\bigcirc)$ spontaneous activity subtracted from the evoked response. Predorzolamide responses were stable, and responses were significantly reduced at 20 and $30 \mathrm{~min}$ after dorzolamide, with recovery at $40 \mathrm{~min}$. When spontaneous activity was subtracted, it is apparent that dorzolamide almost completely abolished the response to carbonated water.

\section{Experiment 2: immunohistochemistry}

Representative photomicrographs of FLI in the regions analyzed are shown in Figure 5; boxes in the drawings of brainstem sections indicate each corresponding region. Application of carbonated water elicited significantly higher FLI in cells located in the dorsomedial aspect of Vc compared with the application of saline
( $t$ test; $p<0.05)$, flat water ( $t$ test; $p<0.05)$, or no stimulation $(t$ test; $p<0.05)$. Figure $6 A$ shows a photomicrograph of cell nuclei expressing FLI in this region after the application of carbonated water. The brainstem distribution of FLI in one rat subjected to carbonated water treatment is shown in Figure $7 A$. FLI was concentrated in the dorsomedial Vc bilaterally, as well as in ventrolateral Vc, the ventrolateral medulla, and throughout the rostrocaudal extent of NTS bilaterally.

Pretreatment with dorzolamide resulted in a significant reduction in FLI in the dorsomedial Vc. The photomicrograph in Figure $6 B$ of dorsomedial Vc from a dorzolamide-pretreated rat shows a marked reduction in FLI compared with application of carbonated water alone (Fig. $6 A$ ). Figure $7 B$ shows the brainstem distribution of FLI from a dorzolamide-pretreated rat. Note in particular the marked reduction in FLI in the dorsomedial Vc throughout its rostrocaudal extent. This was borne out in the mean FLI counts. Figure $8 A$ plots mean counts of FLI in dorsomedial Vc for each treatment group and shows that the dorzolamide pretreatment, as well as the saline, flat water, and unstimulated control groups, all showed significantly less FLI compared with the carbonated water group. There was also significantly more FLI in the ventrolateral aspect of $\mathrm{Vc}$ in the carbonated water group compared with saline or unstimulated controls (Fig. $8 B$ ). There was a trend toward lower FLI in the dorzolamide group, although this failed to reach statistical significance (Fig. $8 B)$. There were no other between-group differences in FLI in any of the other regions analyzed, except in NTS in which the unstimulated control group showed significantly less FLI compared with the other groups (Fig. 8D).

To control for the possibility that the stimulus application procedure elicited FLI, saline and flat water flow controls were undertaken. The photomicrographs in Figure 6 show that application of saline (Fig. $6 C$ ) and flat water (Fig. 6D) resulted in some FLI in dorsomedial Vc. Figure $7 C$ shows the brainstem distributions of FLI in an individual rat subjected to flat water. The distribution of FLI was qualitatively similar to that evoked by carbonated water (Fig. $7 A$ ), except that there was significantly less FLI in dorsomedial Vc (Fig. 8A). In addition, an unstimulated control group was included to separately assess possible effects of anesthesia and passage of time. There was a total absence of FLI in dorsomedial Vc (Fig. 8A), and significantly lower FLI in the ventrolateral caudalis (Fig. $8 B$ ) and NTS (Fig. $8 D$ ) in this group compared with rats receiving carbonated water. These control 


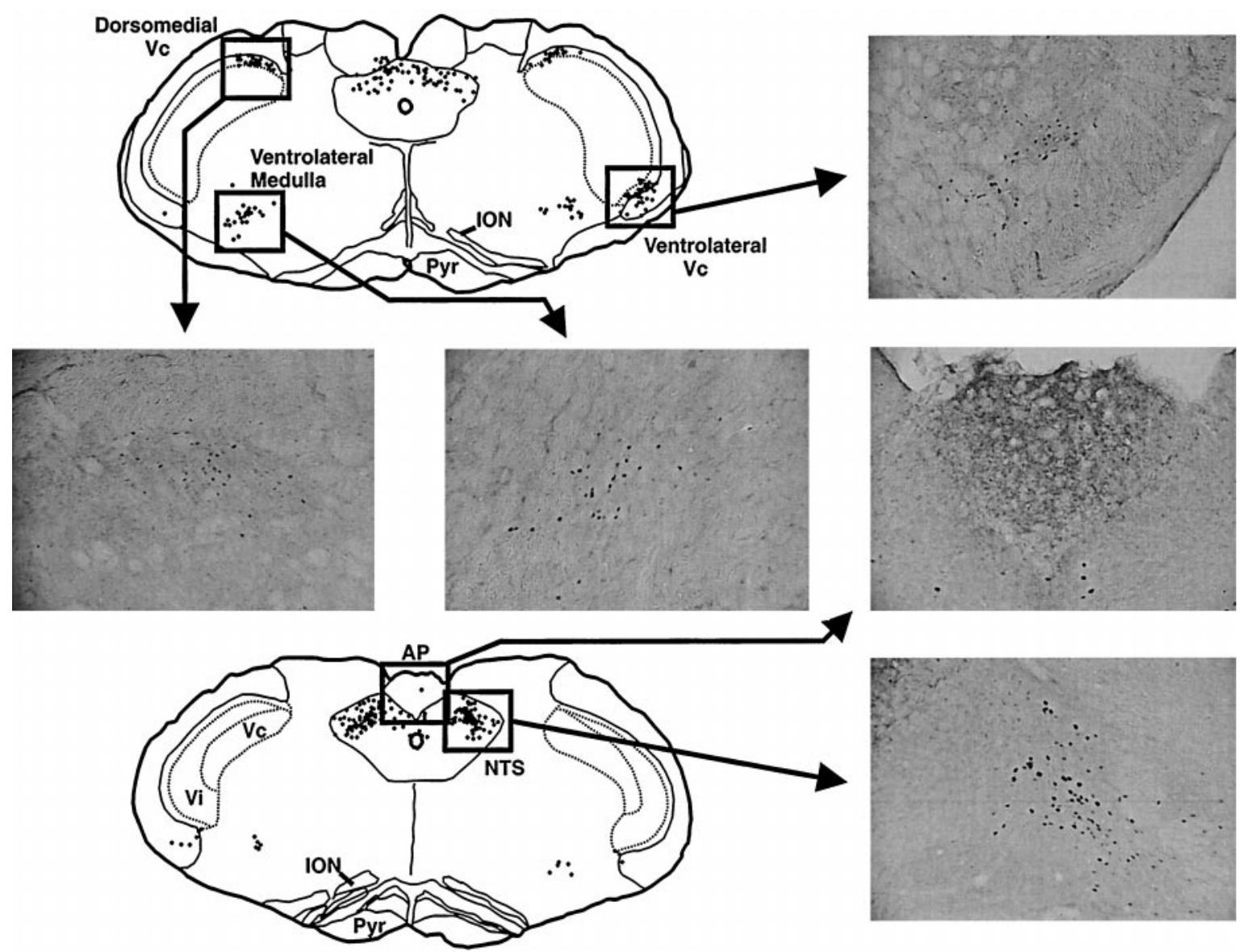

Figure 5. Photomicrographs of regions analyzed for FLI. Each box in top and bottom drawings of brainstem sections corresponds to photomicrograph $(40 \times)$ showing distribution of FLI (black) within that region. Abbreviations as in Figure 7.
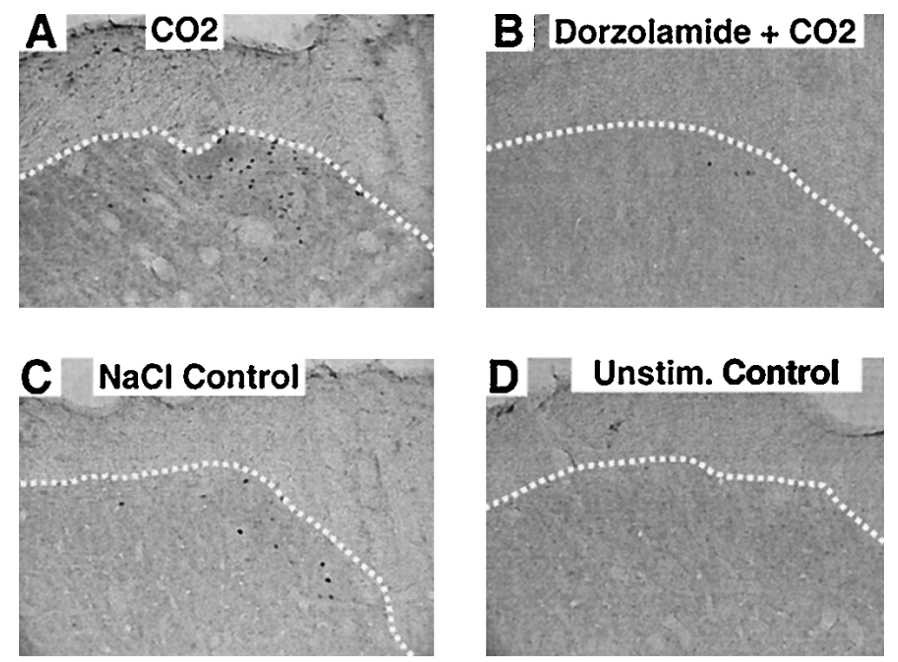

Figure 6. Photomicrographs showing distribution of FLI in the dorsomedial aspect of Vc. $A$, Carbonated water only. B, Pretreatment with dorzolamide, followed by carbonated water. $C$, Isotonic saline $(0.9 \%)$ applied to tongue in same manner as dorzolamide. $D$, Flat water flowed in the same manner as carbonated water.

data indicate that the stimulus application procedures probably induced some FLI by mechanical stimulation of the tongue and/or gustatory effects in NTS, but that this degree of FLI was nonetheless significantly less than that evoked by carbonated water.

\section{Experiment 3: psychophysics}

Carbonated water, when flowed over the tongue for $5 \mathrm{sec}$, elicited a stronger sensation on the side of the tongue not treated with dorzolamide in a significant majority of subjects (18 of 21; binomial; $p<0.001$; equivalent to a $\mathrm{d}^{\prime}$ value of $1.51 ; p<0.01$ ) (Fig. $9 A$ ). When asked to rate the intensity of the carbonation sensation, significantly lower ratings were assigned to the dorzolamidetreated side compared with the untreated side $(4.7 \pm 0.3$ vs $6.2 \pm$ $0.3 ; t$ test; $p<0.001)$. However, when carbonated water was flowed for $15 \mathrm{sec}$, the number of subjects selecting the nontreated side as having the stronger sensation was reduced and no longer significant (14 of 21; binomial; $p=0.19$ ) (Fig. $9 B$ ). The equivalent $\mathrm{d}^{\prime}$ value of 0.61 was not significant $(p=0.13)$. Moreover, after the longer flow, the intensity rating of the treated side reached a level equal to that seen on the untreated side $(6.2 \pm 0.3$ vs $6.2 \pm 0.4$, respectively; $t$ test; $p=1.0$ ).

When the same experiment was conducted using pentanoic acid, the intensity of sensation on the treated and untreated sides of the tongue was similar, indicating that the dorzolamide treatment selectively attenuated the irritation induced by $\mathrm{CO}_{2}$ but not acid (Fig. 9C). Thus, the proportion of subjects choosing the nontreated side as yielding a stronger irritation was not a significant majority (11 of 21 ; binomial; $p=0.66$ ), and the $\mathrm{d}^{\prime}$ value (0.085) was not significant $(p=0.82)$. In addition, the mean intensity rating elicited by the acid on the dorzolamide-treated side was not significantly different from that on the untreated side $(4.2 \pm 0.4$ vs $4.2 \pm 0.4 ; t$ test; $p=1.0)$. 


\section{A. CO2 Control}
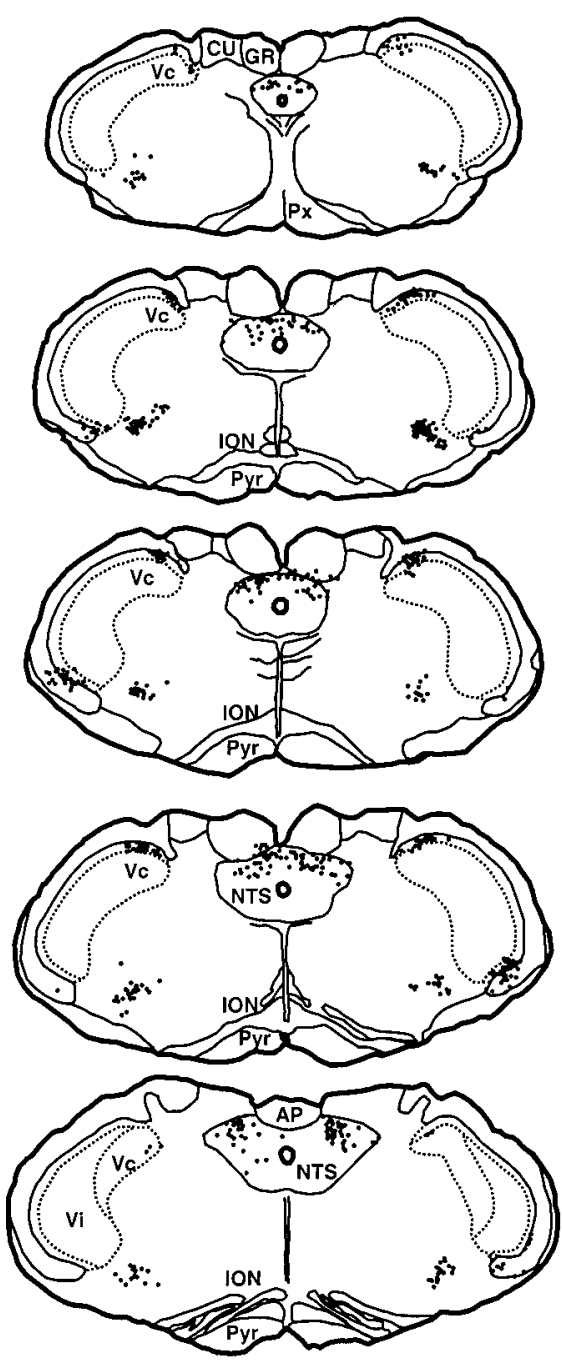

B. Dorzolamide $+\mathrm{CO} 2$
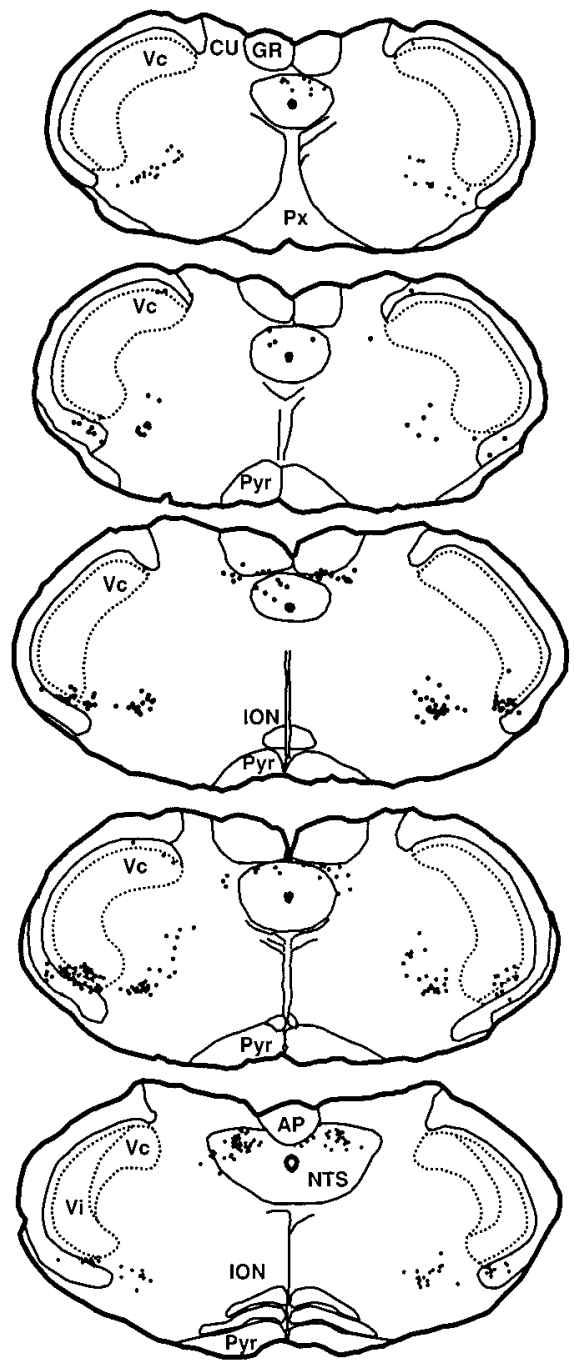

C. Flat Water Control
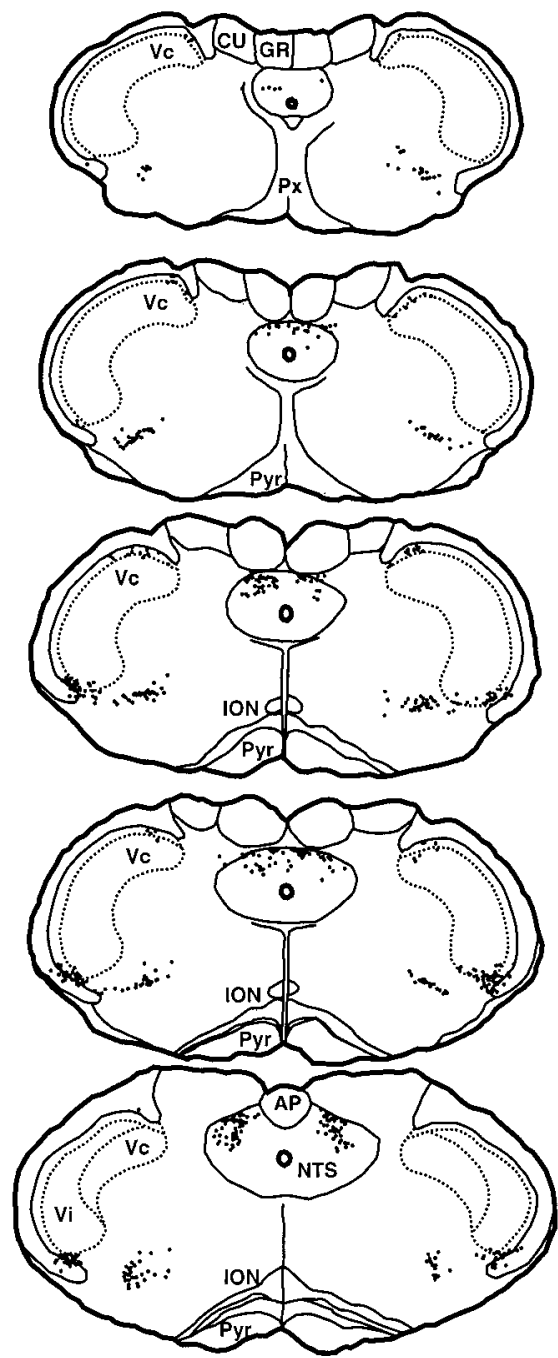

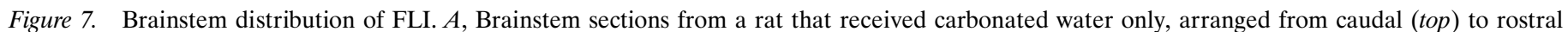

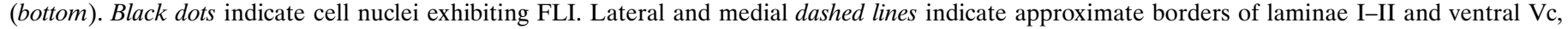

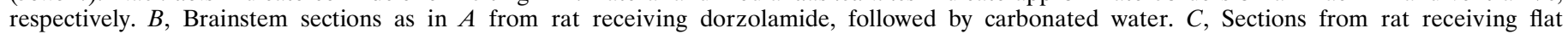

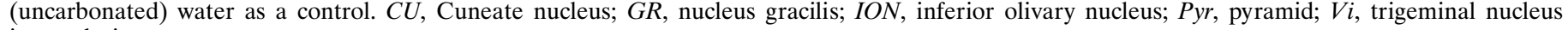
interpolaris.

Pretreatment with dorzolamide had no measurable effect on the tactile sensation produced by the von Frey hair applied to the dorsal surface of the tongue. Mean R-indices representing the tactile sensitivity on the treated and nontreated side were not significantly different (72 vs $71 \%$, respectively; $t$ test; $p=0.44$ ). These measures confirmed that there was no difference in tactile sensitivity between the two sides of the tongue.

After the tasks involving pentanoic acid and tactile sensitivity, we retested the subjects with carbonated water to determine whether the action of the dorzolamide was maintained over the entire test session (30 min). When carbonated water was delivered for $5 \mathrm{sec}$, a significant majority of subjects again selected the untreated side as having the stronger sensation (16 of 21; binomial; $p<0.03)$; this is equivalent to a significant $\mathrm{d}^{\prime}$ value of 1.01 $(p<0.02)$. Similarly, subjects assigned significantly higher intensity ratings to the untreated side $(5.5 \pm 0.4)$ compared with the dorzolamide-treated side $(4.7 \pm 0.3 ; t$ test; $p<0.05)$.

Finally, to control for the effects of taste or texture bias on the collected results, we asked subjects to report which chemical they thought was responsible for reducing the intensity of the sensation evoked by carbonated water. Forty-eight percent (10 of 21) of the subjects selected dorzolamide and 52\% (11 of 21) selected the control solution, thus ruling out a bias in texture or taste as influencing the psychophysical results obtained in this study.

\section{DISCUSSION}

This study investigated the origin of the sensation elicited by the oral application of carbonated water using three complementary methodologies: electrophysiological recordings of single units in Vc, c-Fos immunohistochemistry, and human psychophysics. In each case, the neural activity or perception induced by carbonated water was attenuated by previous treatment of the tongue with the carbonic anhydrase inhibitor dorzolamide. These results independently confirm the chemogenic nature of irritation produced by carbonated water on the tongue. 

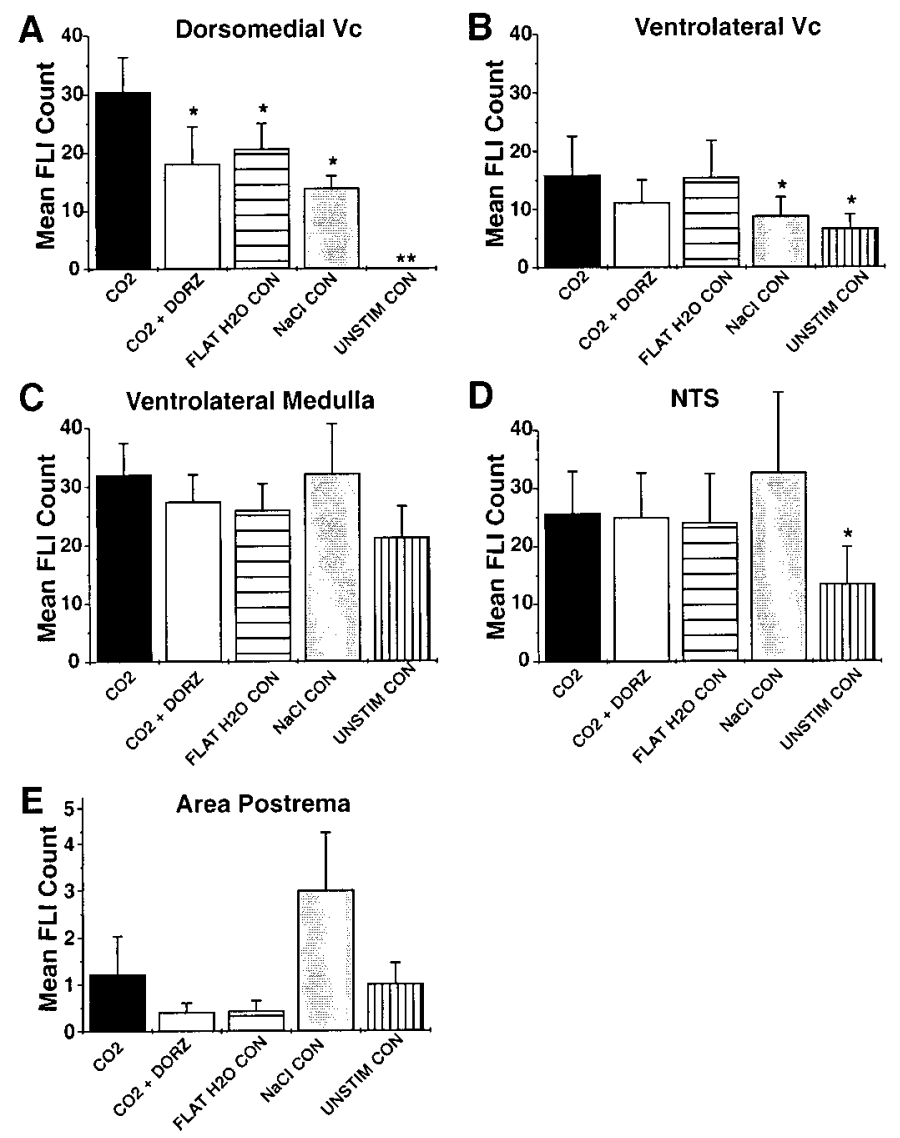

Figure 8. Mean counts of cell nuclei expressing FLI for each region analyzed. $A$, Bar graph plots mean number of cell nuclei expressing FLI in dorsomedial $\mathrm{Vc}$ for each treatment group. $\mathrm{CO}_{2}$, carbonated water only; $\mathrm{CO}_{2}+D O R Z$, pretreatment with dorzolamide, followed by carbonated water; $\mathrm{FLAT} \mathrm{H}_{2} \mathrm{O} C \mathrm{CON}$, flat (uncarbonated) water applied in same manner as carbonated water; $\mathrm{NaCl} C O N, 0.9 \%$ saline applied in same manner as dorzolamide; UNSTIM CON, unstimulated control. $n=5-11$ rats per group. Error bars indicate SEM. ${ }^{*} p<0.05$, significantly different from $\mathrm{CO}_{2}$ group; unpaired $t$ test. $B-E$, Bar graphs as in $A$ for indicated brainstem regions of interest.

\section{Activation of Vc neurons by carbonated water}

The trigeminal nuclear complex is a major relay in the processing of orofacial nociceptive information. Although Vc has been most extensively studied (for review, see Sessle and Greenwood, 1976; $\mathrm{Hu}$ et al., 1981; Dubner and Bennett, 1983), the more rostral subnuclei interpolaris and oralis are also involved (Greenwood and Sessle, 1976; Sessle and Greenwood, 1976; Nord and Young, 1979; Hu et al., 1981, 1992; Hayashi et al., 1984; Hu and Sessle, 1984; Hayashi and Tabata, 1989; Dallel et al., 1990, 1996; Jacquin and Rhoades, 1990; Raboisson et al., 1991; Ohya, 1992; Ohya et al., 1993). Vc processes information from mechanosensitive, proprioceptive, thermosensitive, and nociceptive fibers originating in the orofacial region (Hu et al., 1981; Sessle et al., 1981; Bushnell et al., 1984; Hu, 1990; Chiang et al., 1994; McHaffie et al., 1994; Raboisson et al., 1995), including the oral cavity (Kruger and Michel, 1962; Yokota, 1975; Amano et al., 1986; Strassman and Voss, 1993; Carstens et al., 1995, 1998), nasal sinus (Cain and Murphy, 1980; Garcia Medina and Cain, 1982; Cometto-Muñiz and Noriega, 1985; Stevens and Cain, 1986; Anton et al., 1991a,b, 1992; Thürauf et al., 1991, 1993; Shusterman and Balmes, 1997a,b), and cornea (Belmonte and Giraldez, 1981; Belmonte et
A 5 sec application

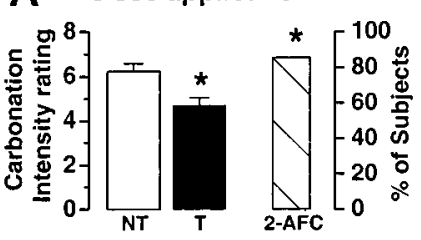

B 15 sec application

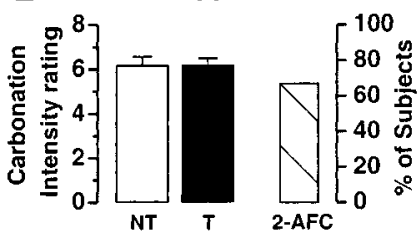

C 5 sec application

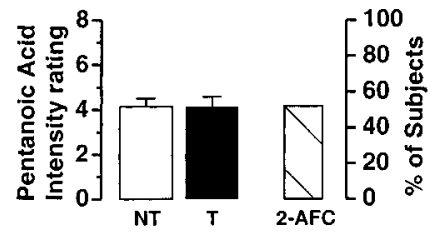

Figure 9. Psychophysical results. A, Bar graph to the left gives intensity ratings of carbonation for the nontreated (NT, open bar) and dorzolamide pretreated ( $T$, filled bar) side of the tongue, respectively. The hatched bar to the right indicates the proportion of subjects who chose the nontreated side to yield a stronger sensation in the 2-AFC test. Ratings were made 5 sec after application of carbonated water to the tongue by continuous flow. Error bars indicate SEM. ${ }^{*} p<0.05$ ( filled bars), significant difference between pretreated and nontreated; $t$ test. ${ }^{*} p<0.05$ (hatched bars), significant majority of subjects chose nontreated side; binomial test. $B$, Graphs as in $A$ for judgements made $15 \mathrm{sec}$ after application of carbonated water. $C$, Graphs as in $A$ showing lack of effect of dorzolamide pretreatment on irritation evoked by pentanoic acid when applied for 5 sec to the tongue.

al., 1991; Pozo and Cervero, 1993; Bereiter et al., 1994; Chen et al., 1995, 1997; Bereiter and Bereiter, 1996; Meng and Bereiter, 1996; Meng et al., 1997; Carstens et al., 1998). We presently found that wide dynamic range-type $\mathrm{Vc}$ units additionally responded to lingual application of carbonated water, indicating that this stimulus is capable of activating trigeminal nociceptive pathways. Furthermore, Vc responses were significantly attenuated by local pretreatment with the carbonic anhydrase inhibitor dorzolamide in a manner that was selective for $\mathrm{CO}_{2}$ but not other acids. These data confirm previous reports that $\mathrm{CO}_{2}$-sensitive primary afferents in the lingual nerve (Komai and Bryant, 1993) and the chorda tympani (Komai et al., 1994) are inhibited by previous application of carbonic anhydrase inhibitors and extend them by showing a selective, carbonic anhydrase-dependent excitatory action of carbonated water at the level of Vc neurons. Thus, the conversion of $\mathrm{CO}_{2}$ to carbonic acid appears to be a requisite step for the excitation of primary nociceptive afferents that transmit signals on $\mathrm{CO}_{2}$ irritation to $\mathrm{Vc}$ and higher centers.

\section{Possible mechanisms underlying actions of $\mathrm{CO}_{2}$ and acids}

Not all Vc units that responded to carbonated water also responded to $\mathrm{HCl}$. Similar results have also been reported for lingual nerve fibers (Komai and Bryant, 1993). One possible explanation is that $\mathrm{CO}_{2}$, being a small lipophilic molecule, can readily diff use through the lingual epithelium and membranes of nociceptive fiber terminals. Thus, $\mathrm{CO}_{2}$ might be capable of activating nociceptors located in deeper layers of the tongue, which are less accessible by protons generated from acids such as $\mathrm{HCl}$ that dissociate at the lingual surface. However, many organic acids are lipophilic, and Bryant and Moore (1995) reported that the efficacy of fatty acids to excite lingual nerve fibers increased as a function of lipophilicity (i.e., carbon chain length). We wished to determine whether more lipophilic acids, comparable with 
$\mathrm{CO}_{2}$ in their ability to penetrate the lingual epithelium, act in a carbonic anhydrase-independent manner. One of these, pentanoic acid, elicited an irritant sensation that was unaffected by dorzolamide, in marked contrast to carbonated water (Fig. 9). This indicates that carbonated water and acidic stimuli activate lingual nociceptors via distinct carbonic anhydrase-dependent and -independent mechanisms, respectively.

It is currently not known whether the carbonic acid formed from $\mathrm{CO}_{2}$ acts intracellulary or extracellularly to excite lingual nerve fiber terminals. In the former instance, $\mathrm{CO}_{2}$ would diff use through the membrane of nociceptor terminals to encounter carbonic anhydrase, which would effect an intracellular acidification resulting in neuronal activation. The presence of carbonic anhydrase within trigeminal ganglion neurons (Wong et al., 1983; Neubauer, 1991) lends support to this hypothesis. Hydrophilic acids such as $\mathrm{HCl}$ would be unable to pass through the cell membrane, requiring instead some extracellular mechanism to excite nociceptors (see below). There is little direct support for the idea of intracellular acidification. In taste receptor cells, increased extracellular $\mathrm{pCO}_{2}$ (with extracellular $\mathrm{pH}$ held constant) produced a transient reduction in intracellular $\mathrm{pH}$ (Lyall et al., 1997), but it is not known whether this depends on intracellular carbonic anhydrase or whether a similar mechanism exists in nociceptors. Alternatively, $\mathrm{CO}_{2}$ may be converted into carbonic acid extracellularly. Carbonic anhydrase is present in saliva (Feldstein and Silverman, 1984; Murakami and Sly, 1987; Fernley et al., 1991). The recent identification of acid-sensing ion channels (ASIC) in sensory neurons could provide the link between extracellular acidification and pain associated with $\mathrm{CO}_{2}$ application (Waldmann et al., 1997b). Extracellular conversion of $\mathrm{CO}_{2}$ into carbonic acid would cause a localized increase in concentration of protons, which could then activate nociceptors via gating of ASIC or dorsal root acid-sensing ion channels presumably located in the membrane of nociceptor fiber terminals (Lingueglia et al., 1997; Waldmann et al., 1997a). Additional transduction mechanisms, such as direct depolarization of nociceptor terminals via proton influx through proton or $\mathrm{Na}^{+}$channels, may also participate in the activation of nociceptors by acidic stimuli.

\section{Immunohistochemistry}

The c-Fos immunohistochemical studies confirmed the electrophysiological results by showing that the FLI induced by carbonated water in dorsomedial Vc is significantly reduced by pretreating the tongue with dorzolamide. This provides further support for the chemogenic nature of sensations elicited by carbonated water.

The Vc shares attributes with the dorsal horn of the spinal cord (Dubner and Bennett, 1983). Superficial layers of Vc are analogous to laminae I-II in the dorsal horn, whereas the magnocellular region corresponds to spinal dorsal horn layers III-IV (Gobel et al., 1988). Nociceptive neurons are found in the superficial layers of Vc (Pozo and Cervero, 1993; Meng et al., 1997; Carstens et al., 1998). Our data support the critical role for Vc in mediating oral $\mathrm{CO}_{2}$ irritation because it, but not other brainstem regions, showed a significant decrease in FLI after dorzolamide application.

Counts of FLI in the NTS were significantly lower in the unstimulated control group compared with all others (Fig. 8D), suggesting that mechanical (e.g., flow), as well as chemical irritant $\left(\mathrm{CO}_{2}\right)$ or taste $(\mathrm{NaCl})$ aspects of the stimuli, may have contributed to FLI in NTS.

\section{Psychophysics}

The present psychophysical data corroborate the neurobiological results by showing that the sensation elicited by carbonated water is significantly attenuated by pretreatment with dorzolamide. That dorzolamide treatment did not affect irritation induced by pentanoic acid, or tactile sensitivity, indicates that its effect was selective for carbonated water and was not attributable to a nonspecific anesthetic action. Thus, these data support the emerging hypothesis that the perception of oral carbonation is attributable to the conversion of $\mathrm{CO}_{2}$ into carbonic acid, which is then capable of exciting lingual chemosensitive nociceptors projecting to Vc (Green, 1992; Komai and Bryant, 1993; Komai et al., 1994; Carstens et al., 1998).

When the carbonated water was flowed for $15 \mathrm{sec}$ compared with $5 \mathrm{sec}$, subjects no longer perceived the dorzolamidepretreated side of the tongue as having a weaker sensation (Fig. $9 B$ ). This was not caused by a washout of dorzolamide, because subjects thoroughly rinsed before the initial $5 \mathrm{sec}$ test with carbonation yet still reported significant differences between the two sides of the tongue. Furthermore, when the carbonation test was repeated (after intervening tests for acid and tactile sensation), a significant majority still chose the nontreated side as having the stronger sensation. One possible explanation is that dorzolamide, although lipophilic, is not as membrane-permeable as $\mathrm{CO}_{2}$. Therefore, with a longer stimulus period, $\mathrm{CO}_{2}$ might activate more distant nociceptors that dorzolamide did not reach. Also, as the duration of $\mathrm{CO}_{2}$ stimulation increases, other factors, such as stimulation of mechanoreceptors, may contribute to the perception of carbonation. In support of this, subjects never assigned an intensity rating of zero to the dorzolamide-treated side, although this might also be explained by incomplete inhibition of carbonic anhydrase or subject response bias. Finally, subjects rated the intensity of the untreated side to be equal in magnitude for both the 5 and $15 \mathrm{sec}$ stimulation periods. This runs counter to what would be expected because, as $\mathrm{CO}_{2}$ penetrates deeper into epithelial tissue, it should recruit more nociceptors, evoking a stronger sensation because of spatial summation. Speculatively, however, nociceptive fibers might desensitize to $\mathrm{CO}_{2}$ at a rate equal to which new fibers are recruited.

\section{REFERENCES}

Amano N, Hu JW, Sessle BJ (1986) Responses of neurons in feline trigeminal subnucleus caudalis (medullary dorsal horn) to cutaneous, intraoral, and muscle afferent stimuli. J Neurophysiol 55:227-243.

Anton F, Herdegen T, Peppel P, Leah JD (1991a) c-Fos-like immunoreactivity in rat brainstem neurons following noxious chemical stimulation of the nasal mucosa. Neuroscience 41:629-641.

Anton F, Peppel P, Euchner I, Handwerker HO (1991b) Controlled noxious chemical stimulation: responses of rat trigeminal brainstem neurones to $\mathrm{CO} 2$ pulses applied to the nasal mucosa. Neurosci Lett 123:208-211.

Anton F, Euchner I, Handwerker HO (1992) Psychophysical examination of pain induced by defined $\mathrm{CO}_{2}$ pulses applied to the nasal mucosa. Pain 49:53-60.

Belmonte C, Giraldez F (1981) Responses of cat corneal sensory receptors to mechanical and thermal stimulation. J Physiol (Lond) 321:355-368.

Belmonte C, Gallar J, Pozo MA, Rebollo I (1991) Excitation by irritant chemical substances of sensory afferent units in the cat's cornea. J Physiol (Lond) 437:709-725.

Bereiter DA, Bereiter DF (1996) $N$-methyl-D-aspartate and non- $N$ methyl-D-aspartate receptor antagonism reduces Fos-like immunoreactivity in central trigeminal neurons after corneal stimulation in the rat. Neuroscience 73:249-258.

Bereiter DA, Hathaway CB, Benetti AP (1994) Caudal portions of the spinal trigeminal complex are necessary for autonomic responses and 
display Fos-like immunoreactivity after corneal stimulation in the cat. Brain Res 657:73-82.

Beverage Digest (1998) 1997 retail value of the carbonated soft drink business in the US only: $\$ 54.7$ billion. February 20:1.

Bi J, Ennis DM, O'Mahony M (1997) How to estimate and use the variance of d' from difference tests. J Sensory Studies 12:87-104.

Bryant BP, Moore PA (1995) Factors affecting the sensitivity of the lingual trigeminal nerve to acids. Am J Physiol 268:R58-R65.

Bushnell MC, Duncan GH, Dubner R, He LF (1984) Activity of trigeminothalamic neurons in medullary dorsal horn of awake monkeys trained in a thermal discrimination task. J Neurophysiol 52:170-187.

Cain WS, Murphy CL (1980) Interaction between chemoreceptive modalities of odour and irritation. Nature 284:255-257.

Carstens E, Saxe I, Ralph R (1995) Brainstem neurons expressing c-Fos immunoreactivity following irritant chemical stimulation of the rat's tongue. Neuroscience 69:939-953.

Carstens E, Kuenzler N, Handwerker HO (1998) Activation of neurons in rat trigeminal subnucleus caudalis by different irritant chemicals applied to oral or ocular mucosa. J Neurophysiol 80:465-492.

Chen X, Gallar J, Pozo MA, Baeza M, Belmonte C (1995) $\mathrm{CO}_{2}$ stimulation of the cornea: a comparison between human sensation and nerve activity in polymodal nociceptive afferents of the cat. Eur J Neurosci 7:1154-1163.

Chen X, Belmonte C, Rang HP (1997) Capsaicin and carbon dioxide act by distinct mechanisms on sensory nerve terminals in the cat cornea. Pain 70:23-29.

Chiang CY, Hu JW, Sessle BJ (1994) Parabrachial area and nucleus raphe magnus-induced modulation of nociceptive and nonnociceptive trigeminal subnucleus caudalis neurons activated by cutaneous or deep inputs. J Neurophysiol 71:2430-2445.

Coimbra F, Coimbra A (1994) Dental noxious input reaches the subnucleus caudalis of the trigeminal complex in the rat, as shown by c-Fos expression upon thermal or mechanical stimulation. Neurosci Lett 173:201-204.

Cometto-Muñiz JE, Noriega G (1985) Gender differences in the perception of pungency. Physiol Behav 34:385-389.

Cometto-Muñiz JE, García-Medina MR, Calviño AM, Noriega G (1987) Interactions between $\mathrm{CO}_{2}$ oral pungency and taste. Perception 16:629-640.

Cowart BJ (1998) The addition of $\mathrm{CO}_{2}$ to traditional taste solutions alters taste quality. Chem Senses 23:397-402.

Dallel R, Raboisson P, Woda A, Sessle BJ (1990) Properties of nociceptive and non-nociceptive neurons in trigeminal subnucleus oralis of the rat. Brain Res 521:95-106.

Dallel R, Luccarini P, Molat JL, Woda A (1996) Effects of systemic morphine on the activity of convergent neurons of spinal trigeminal nucleus oralis in the rat. Eur J Pharmacol 314:19-25.

Dessirier JM, O'Mahony M, Carstens E (1997) Oral irritant effects of nicotine: psychophysical evidence for decreased sensation following repeated application and lack of cross-desensitization to capsaicin. Chem Senses 22:483-492.

Dessirier JM, O'Mahony M, Sieffermann JM, Carstens E (1998) Mecamylamine inhibits nicotine but not capsaicin irritation on the tongue: psychophysical evidence that nicotine and capsaicin activate separate molecular receptors. Neurosci Lett 240:65-68.

Dubner R, Bennett GJ (1983) Spinal and trigeminal mechanisms of nociception. Annu Rev Neurosci 6:381-418.

Ennis DM (1993) The power of sensory discrimination methods. J Sensory Studies 8:353-370.

Feldstein JB, Silverman DN (1984) Purification and characterization of carbonic anhydrase from the saliva of the rat. J Biol Chem 259:5447-5453.

Fernley RT, Wright RD, Coghlan JP (1991) Radioimmunoassay of carbonic anhydrase V I in saliva and sheep tissues. Biochem J 274:313-316.

Forster C, Handwerker HO (1990) Automatic classification and analysis of microneurographic spike data using a PC/AT. J Neurosci Methods 31:109-118.

Garcia Medina MR, Cain WS (1982) Bilateral integration in the common chemical sense. Physiol Behav 29:349-353.

Gobel S, Hockfield S, Ruda MA (1988) Anatomical similarities between medullary and spinal dorsal horns. In: Oral-facial sensory and motor functions (Kawamura Y, Dubner R, eds), pp 211-223. Tokyo: Quintessence.

Graber M, Kelleher S (1988) Side effects of acetazolamide: the champagne blues [letter]. Am J Med 84:979-980.
Green BG (1992) The effects of temperature and concentration on the perceived intensity and quality of carbonation. Chem Senses 17:435-450.

Greenwood LF, Sessle BJ (1976) Inputs to trigeminal brain stem neurones from facial, oral, tooth pulp and pharyngolaryngeal tissues. II. Role of trigeminal nucleus caudalis in modulating responses to innocuous and noxious stimuli. Brain Res 117:227-238.

Hayashi H (1985) Morphology of terminations of small and large myelinated trigeminal primary afferent fibers in the cat. J Comp Neurol 240:71-89.

Hayashi H, Tabata T (1989) Physiological properties of sensory trigeminal neurons projecting to mesencephalic parabrachial area in the cat. J Neurophysiol 61:1153-1160.

Hayashi H, Sumino R, Sessle BJ (1984) Functional organization of trigeminal subnucleus interpolaris: nociceptive and innocuous afferent inputs, projections to thalamus, cerebellum, and spinal cord, and descending modulation from periaqueductal gray. J Neurophysiol 51:890-905.

Hu JW (1990) Response properties of nociceptive and non-nociceptive neurons in the rat's trigeminal subnucleus caudalis (medullary dorsal horn) related to cutaneous and deep craniofacial afferent stimulation and modulation by diff use noxious inhibitory controls. Pain 41:331-345.

Hu JW, Sessle BJ (1984) Comparison of responses of cutaneous nociceptive and nonnociceptive brain stem neurons in trigeminal subnucleus caudalis (medullary dorsal horn) and subnucleus oralis to natural and electrical stimulation of tooth pulp. J Neurophysiol 52:39-53.

Hu JW, Dostrovsky JO, Sessle BJ (1981) Functional properties of neurons in cat trigeminal subnucleus caudalis (medullary dorsal horn). I. Responses to oral-facial noxious and nonnoxious stimuli and projections to thalamus and subnucleus oralis. J Neurophysiol 45:173-192.

Hu JW, Sessle BJ, Raboisson P, Dallel R, Woda A (1992) Stimulation of craniofacial muscle afferents induces prolonged facilitatory effects in trigeminal nociceptive brain-stem neurones. Pain 48:53-60.

Jacquin MF, Rhoades RW (1990) Cell structure and response properties in the trigeminal subnucleus oralis. Somatosens Mot Res 7:265-288.

Jacquin MF, Renehan WE, Mooney RD, Rhoades RW (1986) Structure-function relationships in rat medullary and cervical dorsal horns. I. Trigeminal primary afferents. J Neurophysiol 55:1153-1186.

Kawamura Y, Adachi A (1967) Electrophysiological analysis of taste effectiveness of soda water and $\mathrm{CO}_{2}$ gas. In: Olfaction and taste II (Hayashi T, ed), pp 431-437. New York: Pergamon.

Komai M, Bryant BP (1993) Acetazolamide specifically inhibits lingual trigeminal nerve responses to carbon dioxide. Brain Res 612:122-129.

Komai M, Bryant B, Takeda T, Suzuki H, Kimura S (1994) The effect of topical treatment with a carbonic anhydrase inhibitor, MK-927, on the response of the chorda tympani nerve to carbonated water. In: Olfaction and Taste XI (Kurikara K, Suzuki N, Ogawa H, eds), p 92. Tokyo: Springer.

Kruger L, Michel F (1962) A single neuron analysis of buccal cavity representation in the sensory trigeminal complex of the cat. Arch Oral Biol 7:491-503.

Lingueglia E, de Weille JR, Bassilana F, Heurteaux C, Sakai H, Waldmann R, Lazdunski M (1997) A modulatory subunit of acid sensing ion channels in brain and dorsal root ganglion cells. J Biol Chem 272:29778-29783.

Lotsch J, Hummel T, Kraetsch H-G, Kobal G (1998) Trigeminal chemosensitivity: differences in relation to the time of day. Chem Senses 23:755-759.

Lyall V, Feldman GM, Heck GL, DeSimone JA (1997) Effects of extracellular $\mathrm{pH}, \mathrm{PCO}_{2}$ and $\mathrm{HCO}_{3}$ on intracellular $\mathrm{pH}$ in isolated rat taste buds. Am J Physiol 273:C1008-C1019.

McEvoy S (1998) Sensory evaluation of carbonated beverages utilizing a hyperbaric chamber or what would soda taste like if you could get inside the can? In: Chemical senses day XIV abstracts. Santa Rosa, CA.

McHaffie JG, Larson MA, Stein BE (1994) Response properties of nociceptive and low-threshold neurons in rat trigeminal pars caudalis. J Comp Neurol 347:409-425.

Meng ID, Bereiter DA (1996) Differential distribution of Fos-like immunoreactivity in the spinal trigeminal nucleus after noxious and innocuous thermal and chemical stimulation of rat cornea. Neuroscience $72: 243-254$.

Meng ID, Hu JW, Benetti AP, Bereiter DA (1997) Encoding of corneal input in two distinct regions of the spinal trigeminal nucleus in the rat: cutaneous receptive field properties, responses to thermal and chemical 
stimulation, modulation by diffuse noxious inhibitory controls, and projections to the parabrachial area. J Neurophysiol 77:43-56.

Murakami H, Sly WS (1987) Purification and characterization of human salivary carbonic anhydrase. J Biol Chem 262:1382-1388.

Neubauer JA (1991) Carbonic anhydrase and sensory function in the central nervous system. In: The Carbonic anhydrases: cellular physiology and molecular genetics (Dodgson SJ, Tashian RE, Gres G, Carter ND, eds), pp 319-323. New York: Plenum.

Nord SG, Young RF (1979) Effects of chronic descending tractotomy on the response patterns of neurons in the trigeminal nuclei principalis and oralis. Exp Neurol 65:355-372.

Ohya A (1992) Responses of trigeminal subnucleus interpolaris neurons to afferent inputs from deep oral structures. Brain Res Bull 29:773-781.

Ohya A, Tsuruoka M, Imai E, Fukunaga H, Shinya A, Furuya R, Kawawa T, Matsui Y (1993) Thalamic- and cerebellar-projecting interpolaris neuron responses to afferent inputs. Brain Res Bull 32:615-621.

O'Mahony M (1992) Understanding discrimination tests: a user friendly treatment of response bias, rating and ranking R-index tests and their relationship to signal detection. J Sensory Studies 7:1-47.

Peppel P, Anton F (1993) Responses of rat medullary dorsal horn neurons following intranasal noxious chemical stimulation: effects of stimulus intensity, duration, and interstimulus interval. J Neurophysiol 70:2260-2275.

Pozo MA, Cervero F (1993) Neurons in the rat spinal trigeminal complex driven by corneal nociceptors: receptive-field properties and effects of noxious stimulation of the cornea. J Neurophysiol 70:2370-2378.

Raboisson P, Bourdiol P, Dallel R, Clavelou P, Woda A (1991) Responses of trigeminal subnucleus oralis nociceptive neurones to subcutaneous formalin in the rat. Neurosci Lett 125:179-182.

Raboisson P, Dallel R, Clavelou P, Sessle BJ, Woda A (1995) Effects of subcutaneous formalin on the activity of trigeminal brain stem nociceptive neurones in the rat. J Neurophysiol 73:496-505.

Sessle BJ, Greenwood LF (1976) Inputs to trigeminal brain stem neurones from facial, oral, tooth pulp and pharyngolaryngeal tissues. I. Responses to innocuous and noxious stimuli. Brain Res 117:211-226.

Sessle BJ, Hu JW, Dubner R, Lucier GE (1981) Functional properties of neurons in cat trigeminal subnucleus caudalis (medullary dorsal horn). II. Modulation of responses to noxious and nonnoxious stimuli by periaqueductal gray, nucleus raphe magnus, cerebral cortex, and afferent influences, and effect of naloxone. J Neurophysiol 45:193-207.
Shusterman D, Balmes J (1997a) Measurement of nasal irritant sensitivity to pulsed carbon dioxide: a pilot study. Arch Environ Health $52: 334-340$.

Shusterman DJ, Balmes JR (1997b) A comparison of two methods for determining nasal irritant sensitivity. Am J Rhinol 11:371-378.

Steen KH, Reeh PW, Anton F, Handwerker HO (1992) Protons selectively induce lasting excitation and sensitization to mechanical stimulation of nociceptors in rat skin in vitro. J Neurosci 12:86-95.

Stevens JC, Cain WS (1986) Aging and the perception of nasal irritation. Physiol Behav 37:323-328.

Strassman AM, Vos BP (1993) Somatotopic and laminar organization of fos-like immunoreactivity in the medullary and upper cervical dorsal horn induced by noxious facial stimulation in the rat. J Comp Neurol 331:495-516.

Thürauf N, Friedel I, Hummel C, Kobal G (1991) The mucosal potential elicited by noxious chemical stimuli with $\mathrm{CO}_{2}$ in rats: is it a peripheral nociceptive event? Neurosci Lett 128:297-300.

Thürauf N, Hummel T, Kettenmann B, Kobal G (1993) Nociceptive and reflexive responses recorded from the human nasal mucosa. Brain Res 629:293-299.

Waldmann R, Bassilana F, de Weille J, Champigny G, Heurteaux C, Lazdunski M (1997a) Molecular cloning of a non-inactivating protongated $\mathrm{Na}^{+}$channel specific for sensory neurons. J Biol Chem 272:20975-20978.

Waldmann R, Champigny G, Bassilana F, Heurteaux C, Lazdunski M (1997b) A proton-gated cation channel involved in acid-sensing. Nature 386:173-177.

Wong V, Barrett CP, Donati EJ, Eng LF, Guth L (1983) Carbonic anhydrase activity in first-order sensory neurons of the rat. J Histochem Cytochem 31:293-300.

Yau NJ, McDaniel MR (1990) The power function of carbonation. J Sensory Studies 5:117-128.

Yau NJN, McDaniel MR (1991) The effect of temperature on carbonation perception. Chem Senses 16:337-348.

Yau NJN, McDaniel MR (1992) Carbonation interactions with sweetness and sourness. J Food Sci 57:1412-1416.

Yokota T (1975) Excitation of units in marginal rim of trigeminal subnucleus caudalis elicited by tooth pulp stimulation. Brain Res 95:154-158. 